\title{
Intervenções de Pensamento Computacional na Educação Básica através de Computação Desplugada
}

\author{
Francisco T. S. S. Pereira ${ }^{1}$, Luis Gustavo J. Araújo ${ }^{1}$, Roberto A. Bittencourt ${ }^{1}$ \\ ${ }^{1}$ UEFS - Universidade Estadual de Feira de Santana \\ Av. Transnordestina, s/n, Novo Horizonte \\ Feira de Santana - BA, Brasil - 44036-900 \\ \{franncisco.p, luisaraujo.ifba\}@gmail.com, roberto@uefs.br
}

\begin{abstract}
Computers play an important role in the contemporary society, whether in personal, school or profession-related tasks. Such role requires the mastery of Computational Thinking (CT) skills to solve problems, which is beyond the skills needed to interact with such devices. Therefore, teaching $C T$ in basic education is important to provide this background as well as the exercise of creativity. In this work, we present an experience of teaching CT to middle school students of a public school through Unplugged Computing activities. Results show student engagement and an open field for interdisciplinary work involving CT and disciplines such as Mathematics.
\end{abstract}

Resumo. Atualmente, os computadores ocupam um papel importante na sociedade, seja em tarefas pessoais, escolares ou relacionadas às profissões. Este papel exige, além da capacidade de interagir com esses dispositivos, o domínio de habilidades de pensamento computacional $(P C)$ para resolver problemas. Assim, o ensino de Pensamento Computacional (PC) torna-se necessário na educação básica para proporcionar estes fundamentos e o exercício da criatividade. Neste trabalho, apresentamos uma experiência de ensino de PC para estudantes da educação fundamental de uma escola pública através de atividades de Computação Desplugada. Os resultados demonstram engajamento dos estudantes e um campo aberto para trabalhos interdisciplinares envolvendo PC e disciplinas como Matemática.

\section{Introdução}

Diversas habilidades necessárias na sociedade contemporânea podem ser exercitadas através de atividades relacionadas com a Computação, em especial, as relacionadas ao Pensamento Computacional (PC). Este termo envolve resolver problemas ou projetar algo através de conceitos computacionais, atividades que não se restringem a cientistas da Computação [Wing 2006].

Atividades de Computação Desplugada [Bell et al. 2009] permitem exercitar o pensamento computacional. Assim, ao aliar PC e atividades desplugadas, pode-se exercitar habilidades diversas como resolução de problemas, abstração, decomposição, pensamento algorítmico e avaliação.

Diversos pesquisadores e professores têm utilizado PC e atividades desplugadas no ensino Fundamental, no intuito de oferecer aos estudantes o exercício dessas habilidades do Século XXI. Pinho e colaboradores (2016), por exemplo, aplicaram atividades de 
VIII Congresso Brasileiro de Informática na Educação (CBIE 2019)

Anais do XXV Workshop de Informática na Escola (WIE 2019)

Pensamento Computacional através de metodologias desplugadas com crianças de 10 a 13 anos de idade. Vieira et al. (2013), por sua vez, relatam a aplicação de atividades em escolas públicas utilizando dança, música e teatro para ensinar conceitos como Detecção de Erros, Criptografia e Números Binários. Um mapeamento sistemático realizado por Santos et al. (2018) aponta que atividades desplugadas são mais utilizadas no Ensino Fundamental [Santos et al. 2018].

Este trabalho objetiva apresentar uma abordagem de ensino-aprendizagem de Pensamento Computacional através de atividades desplugadas aplicada em quatro turmas do sexto ano de uma escola pública do Ensino Fundamental II.

\section{Trabalhos Relacionados}

Segundo Wing, Pensamento Computacional "envolve resolver problemas, projetar sistemas e compreender o comportamento humano, baseando-se nos conceitos fundamentais para ciência da computação" [Wing 2006]. Ou seja, trata-se de utilizar conceitos computacionais para atividades diárias ou profissionais. Uma definição mais precisa de pensamento computacional evidencia os termos que aparecem consistentemente na literatura de educação em computação entre 2006 e 2013 [Selby and Woollard 2013]. Na definição proposta, pensamento computacional é um processo cognitivo focado na resolução de problemas e que reflete a capacidade de pensar em termos de abstrações, decomposição, algoritmos, avaliação e generalização.

Brennan e Resnick (2012), por sua vez, descrevem os conceitos de pensamento computacional mais úteis (sequências, loops, paralelismos, eventos, condicionais, operadores e dados), as principais práticas computacionais (ser incremental e iterativo, testar e depurar, reutilizar e remixar, e abstrair e modularizar) e a mudanças de perspectivas observadas em aprendizes: expressão (autoexpressão), conexão (interação com outras pessoas) e questionamento.

O ensino de Pensamento Computacional tem utilizado diversas abordagens [Santos et al. 2018] que vão desde o uso de programação de computadores, com um ambiente lúdico como Scratch ou com uma linguagem textual como Python, até atividades sem o uso de computadores, como as do livro CS Unplugged [Bell et al. 1998].

Dentre outras abordagens, Computação Desplugada se apresenta como uma maneira relevante de se ensinar e aprender Pensamento Computacional. É uma abordagem criada por Bell e colaboradores que visa aplicar atividades sobre conceitos computacionais sem o uso de computadores [Bell et al. 2009]. Atualmente, exitem diversos materiais sobre Computação Desplugada, desde textos e planos de atividades até vídeos. Por sua simplicidade, esta abordagem torna-se ideal em cenários em que não é possível utilizar computadores ou se deseja introduzir algum conceito antes de aplicá-lo com o uso do computador.

Dentre as habilidades do século 21 [Saavedra and Opfer 2012], atividades que envolvem PC cobrem tópicos como Agilidade e Adaptabilidade, Acesso e Análise da Informação, Curiosidade e Imaginação. Tais atividades, quando utilizadas metodologias desplugadas, podem cobrir Iniciativa e Empreendedorismo, Eficiência Oral e Comunicação Escrita, Colaboração e Liderança. Assim, a combinação de PC com atividades desplugadas se mostra propensa a exercitar um conjunto importante de habilidades contemporâneas. 
VIII Congresso Brasileiro de Informática na Educação (CBIE 2019)

Anais do XXV Workshop de Informática na Escola (WIE 2019)

Santos et al. (2018), em um mapeamento sobre Pensamento Computacional, destacam o crescimento no número de trabalhos publicados nesta área nos últimos anos, principalmente na forma de relatos de experiência. De acordo com este mapeamento, as atividades que utilizam computação desplugada são mais frequentes no ensino Fundamental.

Pinho et al. (2016) aplicaram oficinas com sete atividades de 50 minutos baseadas no livro CS Unppluged. As oficinas foram aplicadas em escolas públicas com crianças do quinto ano do Ensino Fundamental. Como resultados, os autores apontam que apesar da variabilidade de resultados pré- e pós-teste, o oficina apresentou resultados positivos. No entanto, apontam a necessidade de melhorar os artefatos de avaliação.

Vieira et al. (2013) relatam a aplicação de oficinas em escolas públicas para estudantes do ensino fundamental e médio, mesclando apresentação de conteúdo através de teatro, narração e atividades desplugadas. Foram cobertos temas como Detecção de Erros, Criptografia e Números Binários. Após as atividades, os alunos avaliaram a abordagem de forma positiva, demonstrando que entenderam os conceitos e que gostariam de mais atividades similares.

Outros trabalhos, como o de Cunha e Nascimento (2018), mesclam a abordagem de Computação Desplugada com Robótica Educacional para estudantes do terceiro, quarto e quinto anos do ensino Fundamental I. O trabalho demonstra como abordagens de Computação Desplugada podem ser utilizadas de maneira interdisciplinar, não apenas com disciplinas do Educação Básica.

Costa et al. (2012) acompanharam atividades das aulas de informática de uma escola privada com duas turmas do $9^{\circ}$ ano do ensino fundamental. Para incentivar os estudantes a aprender fundamentos e abstrações da computação, foram realizadas atividades desplugadas com formato de gincana baseadas no livro CS Unppluged. Os observadores perceberam que os estudantes entenderam os conteúdos, estimularam o pensamento computacional e trabalharam em grupo.

Ferreira et al. (2015) retratam a importância da interdisciplinaridade na escola e como esta fortalece os conhecimentos dos estudantes, além de evidenciar a interdisciplinaridade da ciência da computação. A experiência aconteceu por meio de intervenções com estudantes do $9^{\circ}$ ano do ensino fundamental e do $1^{\circ}$ e $3^{\circ}$ ano do ensino médio. As atividades foram totalmente desplugadas e conectavam a computação com uma ou mais disciplinas da escola. Ao final, percebeu-se que os professores aceitaram a intervenção e tanto eles como os estudantes sentiam necessidade de saber como funciona a computação.

Silva et al. (2014) entendem que o pensamento computacional é importante para a formação de profissionais e que, no Brasil, o ensino da computação está reservado para os que fazem o ensino superior. Os pesquisadores ensinaram pensamento computacional a professores de uma escola para facilitar a disseminação do assunto, através de oficinas plugadas e desplugadas. A maioria dos participantes pretende trabalhar o aprendido em sala de aula, já que as escolas possuem estrutura para a realização das atividades.

As intervenções contidas neste artigo foram realizadas durante aulas formais de matemática, onde estudantes e professor participaram da intervenção, reforçando a ideia da interdisciplinaridade entre computação e matemática. Diferente das experiências relatadas, as intervenções ocorreram no $6^{\circ}$ ano do ensino fundamental. Além de utilizar 
VIII Congresso Brasileiro de Informática na Educação (CBIE 2019)

Anais do XXV Workshop de Informática na Escola (WIE 2019)

atividades presentes no livro CS Unppluged, o grupo desenvolveu duas novas atividades desplugadas, além de adaptar três atividades que originalmente precisariam de um computador para o contexto de computação desplugada.

\section{Metodologia}

Nesta seção, apresentamos o cenário, os participantes e o planejamento da atividades.

\subsection{Cenário}

A intervenção foi realizada na escola pública estadual Centro Integrado de Educação Assis Chateaubriand (CIEAC), no nível do Ensino Fundamental II. Foram usadas atividades desplugadas criadas pelo grupo de pesquisa ou baseadas no livro CS Unppluged [Bell et al. 1998]. A Tabela 1 apresenta o cenário de aplicação da oficina.

Tabela 1. Cenário de aplicação da intervenção

\begin{tabular}{|c|c|c|c|c|}
\hline Ano & Participantes & Série & Período & Carga Horária \\
\hline 2018 & Uma turma com 40 alunos & $\begin{array}{c}6^{\circ} \text { Ano do Ensino } \\
\text { Fundamental }\end{array}$ & Matutino & 9 horas \\
\hline 2019 & Três turmas com 35 alunos cada & $\begin{array}{c}6^{\circ} \text { Ano do Ensino } \\
\text { Fundamental }\end{array}$ & Matutino & 8 horas \\
\hline
\end{tabular}

$\mathrm{Na}$ escola, as intervenções ocorreram durante o segundo período das aulas de matemática, no horário regular da disciplina. O facilitador da intervenção, um dos autores deste artigo, contou com a disponibilidade de 60 minutos, por semana, para a realização da mesma.

\subsection{Planejamento da intervenção}

O objetivo principal da intervenção foi possibilitar a aprendizagem de conceitos basilares de computação a estudantes do Ensino Fundamental, fazendo com que eles aprendessem brincando, proporcionando uma formação para o exercício de habilidades contemporâneas. Os objetivos específicos foram:

1. Colocar o estudante como centro do processo de aprendizagem;

2. Utilizar a computação desplugada para apoiar a aprendizagem de computação;

3. Proporcionar uma formação em habilidades contemporâneas.

A intervenção foi organizada em nove aulas de 60 minutos, conforme apresentado na Tabela 3.2. Das atividades realizadas, quatro delas foram baseadas no livro CS Unplugged (atividades 1, 2, 8 e 9), três foram adaptações desplugadas que fizemos de puzzles do Code.org (atividades 5,6 e 7), e duas delas foram elaboradas por nosso grupo de pesquisa (atividades 3 e 4, a primeira sobre o funcionamento do computador, a última sobre problemas de funcionamento de computadores).

Ao final de cada aula, foi proposta um atividade relacionada ao assunto abordado no dia. Os estudantes deveriam fazer a atividade em casa e trazê-la na aula seguinte. Assim, antes de apresentar um novo conteúdo, a atividade era corrigida e as dúvidas dos estudantes, sanadas. 
VIII Congresso Brasileiro de Informática na Educação (CBIE 2019)

Anais do XXV Workshop de Informática na Escola (WIE 2019)

Tabela 2: Planejamento resumido das oficinas

\begin{tabular}{|c|c|c|c|}
\hline Dia & Objetivo & Conteúdo & Atividades \\
\hline 1 & $\begin{array}{l}\text { Compreender os números } \\
\text { binários e como são uti- } \\
\text { lizados para representar } \\
\text { informações }\end{array}$ & $\begin{array}{l}\text { i) Definição Formal do } \\
\text { Computador } \\
\text { ii) Conversão entre números } \\
\text { binários e decimais } \\
\text { iii) Representação de } \\
\text { caracteres alfanuméricos }\end{array}$ & $\begin{array}{l}\text { i) Introduzir o conceito de } \\
\text { computador } \\
\text { ii) Discutir sobre o que é um } \\
\text { computador } \\
\text { iii) Exercitar os números } \\
\text { binários }\end{array}$ \\
\hline 2 & $\begin{array}{l}\text { Compreender como as ima- } \\
\text { gens são representadas no } \\
\text { computador, aplicando co- } \\
\text { nhecimento sobre números } \\
\text { binários. }\end{array}$ & $\begin{array}{l}\text { i) Definição de imagem digi- } \\
\text { tal } \\
\text { ii) Definição de pixels e ma- } \\
\text { trizes de pixels } \\
\text { iii) Aplicação dos números } \\
\text { binários em imagens }\end{array}$ & $\begin{array}{l}\text { i) Introduzir o conceito de } \\
\text { imagens digitais } \\
\text { ii) Realizar atividades com } \\
\text { números binários e sua } \\
\text { utilização nas imagens re- } \\
\text { presentadas com pixels }\end{array}$ \\
\hline 3 & $\begin{array}{l}\text { Conhecer as funções de } \\
\text { hardware de entrada, saída, } \\
\text { processamento e armazena- } \\
\text { mento, demonstrando como } \\
\text { o hardware interage para } \\
\text { processar informação. }\end{array}$ & $\begin{array}{l}\text { i) Definição de Hardware e } \\
\text { suas funções de: entrada, } \\
\text { saída, processamento e ar- } \\
\text { mazenamento }\end{array}$ & $\begin{array}{l}\text { i) Introduzir o conceito de hard- } \\
\text { ware } \\
\text { ii) Realizar um atividade teatral } \\
\text { demonstrando o funcionamento } \\
\text { do hardware e seus periféricos }\end{array}$ \\
\hline 4 & $\begin{array}{l}\text { Conhecer os principais pro- } \\
\text { blemas de hardware e soft- } \\
\text { ware, analisando estes pro- } \\
\text { blemas e solucionando-os } \\
\text { a partir de estratégias de } \\
\text { resolução de problemas. }\end{array}$ & $\begin{array}{l}\text { i) Definição de problemas } \\
\text { que podem ser encontrados } \\
\text { em hardware e software } \\
\text { ii) Apresentação de métodos } \\
\text { para resolver os problemas } \\
\text { de hardware e software. }\end{array}$ & $\begin{array}{l}\text { i) Introduzir o conteúdo a par- } \\
\text { tir de um jogo de tabuleiro onde } \\
\text { o jogador irá encontrar alguns } \\
\text { problemas de hardware e soft- } \\
\text { ware e tentar resolvê-los. }\end{array}$ \\
\hline 5 & $\begin{array}{l}\text { Compreender como os } \\
\text { programas de computador } \\
\text { são organizados a partir } \\
\text { de ideias específicas - os } \\
\text { algoritmos. }\end{array}$ & $\begin{array}{l}\text { i) Algoritmos em sequência. } \\
\text { ii) Programas em sequência } \\
\text { em uma linguagem de blo- } \\
\text { cos }\end{array}$ & $\begin{array}{l}\text { i) Introduzir o conceito de algo- } \\
\text { ritmo. } \\
\text { ii) Apresentar o assunto a par- } \\
\text { tir de um modelo físico da ati- } \\
\text { vidade da sequência de labirinto } \\
\text { do site Code.org }\end{array}$ \\
\hline 6 & $\begin{array}{l}\text { Compreender o significado } \\
\text { de loops, e como eles são } \\
\text { utilizados para reduzir o ta- } \\
\text { manho de algoritmos. }\end{array}$ & $\begin{array}{l}\text { i) Algoritmos com loops } \\
\text { ii) Programas com loops em } \\
\text { uma linguagem de blocos }\end{array}$ & $\begin{array}{l}\text { i) Introduzir o conceito de loops } \\
\text { ii) Apresentar o assunto a par- } \\
\text { tir de um modelo físico da ati- } \\
\text { vidade da sequência de labirinto } \\
\text { do site Code.org }\end{array}$ \\
\hline 7 & $\begin{array}{l}\text { Revisar o significado de lo- } \\
\text { ops e aprender noções de } \\
\text { depuração de código }\end{array}$ & $\begin{array}{l}\text { i) Algoritmos com loops } \\
\text { ii) Identificação e correção } \\
\text { de bugs }\end{array}$ & $\begin{array}{l}\text { i) Introduzir o conceito de } \\
\text { correção de bugs } \\
\text { ii) Revisar o conceito de loops } \\
\text { iii) Apresentar o assunto a par- } \\
\text { tir de um modelo físico da ati- } \\
\text { vidade da sequência de labirinto } \\
\text { do site Code.org }\end{array}$ \\
\hline 8 & $\begin{array}{l}\text { Reconhecer padrões que po- } \\
\text { dem ser encontrados em pa- } \\
\text { lavras e textos. }\end{array}$ & $\begin{array}{l}\text { i) Definição de padrão em } \\
\text { palavras e textos } \\
\text { ii) Conhecimento de como } \\
\text { funcionam os computadores }\end{array}$ & $\begin{array}{l}\text { i) A partir de um poema, o aluno } \\
\text { deve procurar as palavras que se } \\
\text { repetem e encontrar padrões. }\end{array}$ \\
\hline 9 & 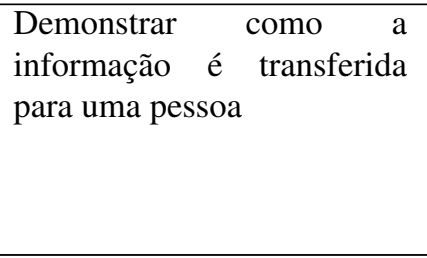 & $\begin{array}{l}\text { i) Definição de informação } \\
\text { ii) Definição de árvore de } \\
\text { decisão }\end{array}$ & $\begin{array}{l}\text { i) Realizar a comparação de } \\
\text { números trabalhando com fai- } \\
\text { xas de valores } \\
\text { ii) Trabalhar com a dedução de } \\
\text { números e formulação de per- } \\
\text { guntas }\end{array}$ \\
\hline
\end{tabular}


VIII Congresso Brasileiro de Informática na Educação (CBIE 2019)

Anais do XXV Workshop de Informática na Escola (WIE 2019)

\section{Nossa Experiência}

Nesta seção, apresentamos os resultados através da descrição de uma narrativa das intervenções. Os resultados apresentados provêm do diário de bordo do oficineiro.

No primeiro dia, fizemos uma introdução da intervenção para os estudantes, apresentando o planejamento. Perguntamos aos estudantes o que eles entendiam por computador. Esta atividade ajudou a reconhecer o nível de conhecimento dos estudantes a respeito deste assunto, já que muitos estudantes não sabiam que uma calculadora é um tipo de computador. Após um debate sobre o assunto, apresentamos uma definição mais formal do computador para os estudantes.

Nessa aula, realizamos uma atividade desplugada sobre números binários. $\mathrm{Na}$ dinâmica, os estudantes iam para a frente da sala de aula e tentavam transformar um número decimal em binário. Os estudantes se mostraram participativos e acharam a atividade divertida. Muitos gostaram de a aula ter uma dinâmica diferente da tradicional.

Ao término da aula, propusemos uma atividade para casa, onde os estudantes deveriam aplicar os conhecimentos através de uma mensagem codificada em números binários. Na atividade, cada sequência de números representava uma letra disponível em uma tabela para consulta. O estudante deveria fazer a decodificação da mensagem e descobrir o significado da mensagem, consultando a tabela.

No início do segundo dia, corrigimos a atividade passada para casa, sanando dúvidas que os estudantes apresentaram. Além disso, o conceito de números binários foi revisado. Observamos que os estudantes ficaram mais entusiasmados no segundo dia de aula, pois muitos demonstraram interesse nos assuntos relacionados à Computação, e realizavam perguntas do tipo: "Como o celular armazena informações?" (E1) e "Como posso melhorar a velocidade do computador?” (E2).

Em seguida, apresentamos como o computador pode representar uma imagem a partir do conceito de pixel, relembrando o conceito de números binários. Para finalizar, propusemos outra atividade para casa, onde os estudantes deveriam desenhar figuras na forma de uma matriz de pixels. Papéis compostos por pequenos quadrados foram disponibilizados e os estudantes deveriam pintar os quadrados com um ou zero, podendo desenhar qualquer figura, de acordo com o solicitado.

Assim como na aula anterior, no terceiro dia, a atividade para casa foi corrigida. Segundo os estudantes, esta foi uma das aulas mais divertidas da oficina, pois o assunto foi consolidado por meio de um teatro em que os atores foram os próprios estudantes, que assumiam os papeis de: usuário (que informa os dados de entrada, neste caso, dois números e uma operação matemática); teclado (que recebe os dados de entrada), CPU (que processa os dados e realiza as contas) e monitor (que exibe o resultado final para o usuário). Esta atividade foi elaborada pelo nosso grupo de pesquisa.

O professor aproveitou a dinâmica para testar os estudantes, explorando o assunto que ele estava ministrando no momento: frações e potência. O professor informava os dados e o estudante que assumiu o papel da CPU realizava a operação e, em seguida, transmitia a informação para o monitor que mostrava o resultado para o professor. Neste dia, os estudantes gostaram de testar as suas habilidades com as operações matemáticas e o professor gostou de utilizar a atividade com o conteúdo específico de sua disciplina. 
VIII Congresso Brasileiro de Informática na Educação (CBIE 2019)

Anais do XXV Workshop de Informática na Escola (WIE 2019)

Assim, esta atividade, embora não idealizada de modo interdisciplinar, mostrou bom potencial para que os professores de outras disciplinas possam trabalhar com conteúdos específicos.

No quarto dia, abordamos o conteúdo programado a partir de um jogo de tabuleiro desenvolvido por nosso grupo de pesquisa. O jogo consiste em rodadas, em que um estudante ou um grupo lança o dado e anda a quantidade de casas indicada pelo dado. O peão do estudante/grupo pode cair em uma casa que demanda a solução de um erro comum com computadores, como problemas de hardware: 1) Problemas com a fonte do computador; 2) Problemas com o cabo (vídeo, som, internet, mouse, impressora); 3) Problema com a internet sem fio; 4) Problema com o monitor. Ou erros ligados a problemas de software: 5) O software parou; 6) O software não abre; 7) A licença do software expirou; 8) O computador travou.

Nos problemas acima, os estudantes deveriam dizer o que fazer para solucioná-los. Caso o peão caísse em uma casa de ações, os estudantes deveriam mostrar o passo a passo de como cada ação típica de uso do computador é realizada utilizado cartas especiais. Cada jogador deve organizar as cartas de forma condizente com a realidade. Caso acerte, o peão irá andar uma quantidade de casas. As cartas de ação são ilustradas na Figura 1: i) Instalar um Software, ii) Desligar o Computador; iii) Imprimir um arquivo; iv) Abrir/Salvar um arquivo; v) Deletar um arquivo; vi) Criar pasta; vii) Colocar/remover um pendrive; viii) Abrir/Fechar um Programa.

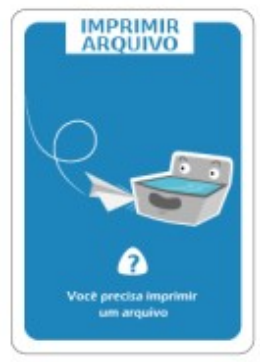

(a) Card de Ação 01

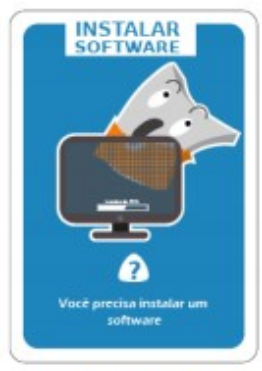

(d) Card de Açã̃o 04

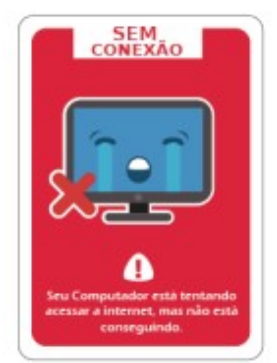

(b) Card de Ação 02

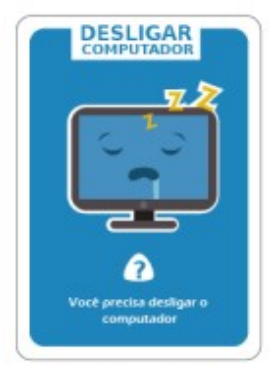

(e) Card de Ação 05

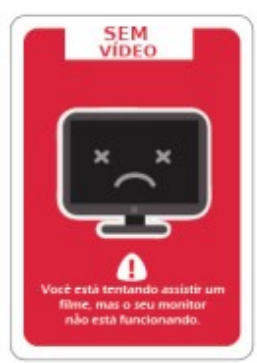

(c) Card de Ação 03

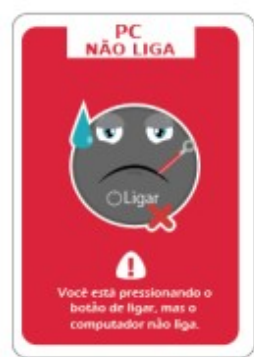

(f) Card de Ação 06

Figura 1. Exemplos de cartas de ação desenvolvidas

Os alunos deveriam percorrer o tabuleiro com os peões até chegar ao final. Como o tabuleiro foi desenvolvido para poucos jogadores, a turma foi dividida em dois grupos criando um ambiente de competição na sala, fator que aparentemente deixou a atividade mais divertida.

Como as turmas da intervenção serviram como testadores do jogo através das 
VIII Congresso Brasileiro de Informática na Educação (CBIE 2019)

Anais do XXV Workshop de Informática na Escola (WIE 2019)

partidas, percebemos que alguns fatores de jogabilidade podem ser modificados para melhorar a dinâmica. Apesar disto, os estudantes demonstraram interesse no jogo, possivelmente pelo fato de ser um jogo de tabuleiro, algo não comumente utilizado em sala.

Na quinta aula, apresentamos o conceito de algoritmo, demonstrando como um programa de computador é criado a partir de sequências de comandos. Antes de começar a aula, perguntamos o que era um algoritmo para eles. Alguns alunos sabiam o significado e se expressavam: "É como fazer um bolo, seguindo uma receita (E3) ou "É seguir alguns passos” (E4). Na aula, utilizamos peças físicas, baseadas nos desafios do labirinto do site Code.org [Code.org 2019], no qual um peão estilizado (no caso, um passarinho) teria que percorrer um caminho para chegar em outro peão (no caso, um porco).

Explicamos aos alunos que o passarinho só conhecia alguns comandos, e pedimos que eles pensassem quais comandos o passarinho deveria seguir para alcançar o porco com sucesso. Neste dia, houve uma participação bastante ativa dos alunos na aula. Ao final, propusemos uma atividade para casa onde o estudante deveria escrever uma sequência de passos que um peão deveria fazer para chegar a outro peão, de modo similar ao que foi exercitado em sala.

No início da sexta aula, a atividade de casa foi corrigida. Explicamos o conteúdo da aula: loops. Como em aulas anteriores, os estudantes foram questionados sobre o que eles entendiam sobre o assunto. Alguns sabiam o que era uma repetição: "É fazer uma coisa mais de uma vez sem parar" (E5). Em seguida, explicamos como uma repetição pode ser utilizada na vida real e nos códigos de programas. Para a explicação, os materiais utilizados na aula anterior foram reaproveitados, inserindo estruturas de repetição no desenvolvimento da solução.

No sétimo dia, explicamos o conceito de depuração e de bugs. Explicamos a origem do termo e como problemas de software podem ser resolvidos. Para explanação sobre o conteúdo, utilizamos o material da aula anterior, demonstrando como um bug pode ser encontrado em determinados trechos de código de um programa.

No oitavo dia, aplicamos uma atividade desplugada que envolve conceitos de português, abordando o reconhecimento de padrões em palavras e textos. Dada uma frase, percebe-se que alguns trechos são repetidos e aproveitados, como por exemplo na palavra banana, em que o trecho an se repete duas vezes.

Para exemplificar, apresentamos o poema "Amor é fogo que arde sem se ver", de Luís Vaz de Camões, em sala de aula. Os estudantes deveriam verificar os trechos que se repetem e encontrar padrões no poema. Embora a interdisciplinaridade nesta atividade não tenha sido provocada, percebe-se que esta atividade permite a interdisciplinaridade com disciplinas de Português e Literatura. Como atividade de casa, propusemos que os estudantes procurassem um poema e identificassem padrões e palavras que se repetem.

A atividade do nono dia consistiu em demonstrar como a informação é transmitida para uma pessoa. Questionamos aos aprendizes o que eles entendiam por informação e como ela pode ser transferida de pessoa para pessoa. A atividade trabalhada em sala consistiu em escolher um aluno para adivinhar um número escolhido previamente através de um palpite. Os colegas responderiam se o palpite era maior, menor ou igual ao número escolhido previamente. Em seguida, foi possível associar a atividade feita em sala com uma árvore de possibilidades. 
VIII Congresso Brasileiro de Informática na Educação (CBIE 2019)

Anais do XXV Workshop de Informática na Escola (WIE 2019)

Para finalizar, realizamos mais uma dinâmica, onde papéis contendo um número foram colados nas testas dos alunos. Cada um deveria tentar adivinhar qual número estava colado em sua testa. Para relembrar o conteúdo das aulas anteriores, os números foram escritos em binário.

\section{Lições Aprendidas}

As principais lições desta experiência se relacionam com a motivação através de desafios, a participação ativa e a interdisciplinaridade oferecidas pela abordagem, além da expectativa do uso do computador.

O uso de desafios é motivador. Nota-se que os estudantes, geralmente, gostam de desafios. A competição que ocorreu durante o quarto dia fez com que os estudantes se dedicassem mais, fazendo com que as atividades fossem realizadas com sucesso e que eles aprendessem de forma dinâmica.

A abordagem possibilita participação ativa. Também foi perceptível que os estudantes gostam de participar ativamente de atividades, fator observado nas aulas em que era solicitada a presença de estudantes na frente da sala para participar de alguma atividade.

A abordagem permite interdisciplinaridade. A interdisciplinaridade é um aspecto promissor nesta abordagem. Durante as aulas, o professor se envolveu em uma das atividades e fez com que a dinâmica utilizasse o assunto de Matemática que ele estava apresentando, fazendo com que, além de os estudantes aprenderem algo novo, pudessem revisar um assunto previamente estudado em outra disciplina. Uma segunda atividade poderia ser utilizada, no mesmo sentido, pelo professor de português.

A abordagem gera expectativa do uso do computador. Computação desplugada permite aprender sobre computação sem o computador. No entanto, provoca expectativas do uso do computador. Muitos estudantes ficaram confusos nas primeiras aulas pois não utilizavam computador. Todavia, eles puderam perceber que que alguns assuntos podem ser ensinados sem a presença física de um computador.

\section{Conclusões}

Esse artigo relatou uma experiência de prática do ensino-aprendizagem de computação desplugada em uma escola do município de Feira de Santana, demonstrando uma outra forma de trabalhar com assuntos envolvendo o mundo da computação para estudantes do sexto ano Ensino Fundamental II.

Percebe-se que a abordagem com o uso da Computação Desplugada, além de permitir a introdução de conceitos de computação, também viabiliza a aplicação da interdisciplinaridade e a participação ativa dos estudantes. O uso de desafios é um elemento motivador na abordagem. No entanto, as aulas geram expectativa nos estudantes de usar o computador, na escola, em algum momento.

Como trabalhos futuros, pretende-se aplicar esta intervenção em outras escolas da rede pública e privada, no Ensino Fundamental II, de modo a compreender com maior profundidade os impactos desta abordagem. Pretende-se também aperfeiçoar os materiais didáticos aplicados, aumentando o número de atividades que podem ser realizadas durante um ano letivo completo. Finalmente, pretendemos avaliar como este tipo de atividade afeta as atitudes de estudantes do ensino fundamental em relação à computação. 
VIII Congresso Brasileiro de Informática na Educação (CBIE 2019)

Anais do XXV Workshop de Informática na Escola (WIE 2019)

\section{Agradecimentos}

Agradecemos aos professores Ernesto e Anatália por tornarem possível a realização deste trabalho. Este projeto foi apoiado pela FAPESP, através do auxílio 2015/24331-1 e da bolsa de treinamento técnico 2018/15614-8, e pela UEFS, através de bolsa de extensão.

\section{Referências}

Bell, T., Alexander, J., Freeman, I., and Grimley, M. (2009). Computer science unplugged: School students doing real computing without computers. The New Zealand Journal of Applied Computing and Information Technology, 13(1):20-29.

Bell, T., Witten, I. H., and Fellows, M. (1998). Computer Science Unplugged... off-line activities and games for all ages.

Brennan, K. and Resnick, M. (2012). New frameworks for studying and assessing the development of computational thinking. In Proceedings of the 2012 annual meeting of the American Educational Research Association, Vancouver, Canada, pages 1-25.

Code.org (2019). O que você criará? https : / / code . org / . [Acesso em 5 Jun. 2019].

Costa, T., Batista, A., Maia, M., Almeida, L., and Farias, A. (2012). Trabalhando Fundamentos de Computação no Nível Fundamental: Experiência de Licenciados em Computação da Universidade Federal da Paraíba. XX WEI.

Cunha, F. and Nascimento, C. R. (2018). Uma Abordagem Baseada em Robótica e Computação Desplugada para Desenvolver o Pensamento Computacional na Educação Básica. In Simpósio Brasileiro de Informática na Educação - SBIE.

Ferreira, A. C., Melhor, A., Barreto, J., de Paiva, L. F., and Matos, E. (2015). Experiência Prática Interdisciplinar do Raciocínio Computacional em Atividades de Computação Desplugada na Educação Básica. In Anais do Workshop de Informática na Escola.

Pinho, G., Weisshahn, Y., Reiser, R., de Brum, C. F., Cavalheiro, S., Foss, L., Aguiar, M., and Du Bois, A. (2016). Pensamento Computacional no Ensino Fundamental: Relato de Atividade de Introdução a Algoritmos. In Anais do XXII WIE.

Reis da Silva, T., Galvão de Araujo, G., and Henrique da Silva Aranha, E. (2014). Oficinas Itinerantes de Scratch e Computação Desplugada para Professores como Apoio ao Ensino de Computação - Um Relato de Experiência. Anais do XX WIE, pages 380-389.

Saavedra, A. R. and Opfer, V. D. (2012). Learning 21st-century skills requires 21stcentury teaching. Phi Delta Kappan, 94(2):8-13.

Santos, P. S. C., Araujo, L. G. J., and Bittencourt, R. A. (2018). A Mapping Study of Computational Thinking and Programming in Brazilian K-12 Education. In 2018 IEEE Frontiers in Education Conference (FIE). IEEE.

Selby, C. and Woollard, J. (2013). Computational thinking: the developing definition.

Vieira, A., Passos, O., and Barreto, R. (2013). Um Relato de Experiência do Uso da Técnica Computação Desplugada. Anais do XXI WEI, pages 670-679.

Wing, J. M. (2006). Computational thinking. Communications of the ACM, 49(3):33-35. 